\title{
Proses Penentuan Harga Desain pada Desainer Grafis Freelance
}

\author{
Lutfi Tri Atmaji \\ Universitas Bina Nusantara \\ email: lutfi.atmaji@binus.ac.id
}

\begin{abstract}
Abstrak
Perkembangan teknologi digital telah menambah semua aspek, termasuk dunia pemasaran. Hal ini membuka peluang bagi bidang desain grafis atau desain komunikasi visual yang dibutuhkan oleh masyarakat. fenomena tersebut dapat dilihat dari maraknya berbagai perguruan tinggi untuk membuka program studi atau jurusan desain grafis/desain komunikasi visual. Para desainer muda lulusan perguruan tinggi tersebut, memiliki berbagai pilihan diantaranya menjadi karyawan perusahaan dan atau sebagai pekerja lepas (freelance). Dalam kasus freelance para desainer muda atau desainer pemula yang belum berpengalaman sering kali memiliki permasalahan menetapkan harga sebuah jasa desain dan rincian biaya produksinya ketika bertemu konsumen. Ketepatan dan rasionalitas rincian biaya desain yang ditawarkan tersebut, sebagai ukuran tingkat keprofesionalan desainer muda tersebut, jika biaya desain yang ditawarkan terkesan tidak rasional maka konsumen sering kali melakukan upaya penawaran yang memungkinkan kesepakatan harga akan merugikan desainer tersebut. Atas dasar fenomena tersebut, fokus artikel ini mengkaji proses apa saja yang perlu disetujui dalam harga bagi para desainer lepas/freelance $r$. Metode penelitian menggunakan metode kualitatif dengan instrumen penelitian berupa wawancara mendalam dan Diskusi Kelompok Terfokus atau FGD. Hasil dari artikel ini membantu para desainer pemula yang baru terjun di dunia freelance dalam menyetujui harga sebuah desain agar dapat membuat layak dan mendapatkan tempat yang tepat dalam industri kreatif modern saat ini.
\end{abstract}

Kata kunci: teknologi digital, desain, penetapan harga

\begin{abstract}
The development of digital technology has influenced various aspects of life, including the world of marketing. This opens opportunities for the field of graphic design or visual communication design that needed by the community. this phenomenon, can be seen from the rise of various universities to open study programs or graphic design majors / visual communication design. The young designers of the college graduates have various choices include being a company employee and or as a freelance worker. In the case of freelance young designers or novice designers who are inexperienced often have problems determining the price of a design service and the details of its production costs when meeting consumers. The accuracy and rationality of the detailed design costs offered, as a measure of the level of professionalism of the young designer, if the design costs offered seem irrational, consumers often make bidding efforts that allow the price agreement to harm the designer. On the basis of this phenomenon, the focus of this article examines what processes need to be approved in price for freelance designers/freelance rs. The research method uses qualitative methods with research instruments in the form of in-depth interviews and Focus Group Discussions or FGDs. The results of this article help beginner designers who have
\end{abstract}


Lutfi Tri Atmaji, Proses Penetuan Harga Desain...

just jumped into the freelance world in agreeing to the price of a design to make it feasible and get the right place in today's modern creative industry.

Keywords: digital technology, visual communication design, pricing

\section{PENDAHULUAN}

Perkembangan teknologi digital yang pesat telah merambah semua aspek tidak terkecuali dengan dunia pemasaran. Dengan hadirnya era digital yang mempermudah pemasaran maka para pelaku ekonomi tentu harus lebih memaksimalkan perkembangan teknologi digital dalam mempromosikan prodak atau jasa. Agar dapat bersaing dalam kerasnya dunia pemasaran maka perlu saling adu kreativitas dalam memasarkan produknya terlebih lagi dengan memanfaatkan media digital maka kreatif advertising merupakan salah satu solusi dalam memaksimalkan pemasaran dengan media digital. Dalam industri keratif dan advertising tentu tidak jauh dari dunia desain terutama desain grafis atau desain komunikasi visual. Dibanding dengan cetak, desain grafis memang lebih dekat dengan dunia pemasaran karena dalam dunia desain grafis atau desain komunikasi visual juga dikaji mengenai pemasaran dan komunikasi. Hal tersebut menjadi sebuah trend positif bagi dunia desain grafis atau desain komunikasi visual (DKV) melihat banyak potensi besar bagi para desainer sehingga permintaan akan para desainer muda cukup besar.

Para desainer muda yang baru menyelesaikan pendidikan desain atau baru lulus umumnya akan dihadapkan pada tiga pilihan yaitu bekerja dengan orang/perusahaan/lembaga, bekerja secara independen atau melanjutkan studi ke jenjang yang lebih tinggi. Desainer grafis yang memilih untuk bekerja secara independen atau berwira usaha di bidang desain umumnya akan mendirikan perusahaan desain berbasis CV sebagai lembaga hukum atau memilih untuk menjadi desainer lepas atau freelance desainer atau desainer independen tanpa memiliki payung lembaga hukum. Biro desain memiliki keunggulan dapat menjangkau project dengan nilai nominal yang besar atau project dengan pemerintah namun untuk mendirikan sebuah biro desain juga tidak murah atau membutuhkan biaya yang tidak sedikit, memiliki SDM yang dapat dipercaya dan diandalkan serta berpayung hukum CV sebagai langkah awal agar lebih dapat dipercaya oleh konsumen sekelas perusahaan atau pemerintah.

Berbeda dengan biro desain, desainer freelance atau desainer grafis independen atau desainer lepas biasa bekerja secara mandiri atau tim. Menurut Surianto Rustan (Rustan, Surianto. (2015). Bisnis Desain Grafis. Jakarta: Batavia Imaji) desainer freelance bekerja mandiri, menjual sendiri jasanya dan tidak terikat pada sebuah agensi/perusahaan tertentu. Freelance desainer juga tidak membutuhkan dana yang besar dan tidak perlu memiliki payung hukum seperti CV atau PT. Proyek atau tender yang didapat juga bisa beraneka ragam tidak terbatas seperti jika seorang desainer terikat oleh agensi atau perusahaan di mana project ditentukan oleh atasan. Namun, jika ingin mendapatkan proyek dengan tender yang besar maka harus memiliki jam terbang tinggi terlebih dahulu atau sudah berpengalaman dan tentunya sudah dikategorikan sebagai profesional dan hal tersebut tidaklah mudah. Desainer grafis independen atau desainer freelance pemula harus bisa menerima risiko mendapat keuntungan kecil di awal karir 
dan tidak selalu mendapat proyek secara berkala, ada saatnya dalam sebulan freelance desainer bahkan tidak mendapat proyek sama sekali sehingga tidak memiliki pemasukan finansial.

Kendala yang umumnya dialami para desainer grafis yang baru terjun di industri desain independenden atau desainer freelance adalah bagaimana menentukan harga desain agar sesuai baik bagi konsumen/klien dan bagi desainer itu sendiri. Tentu terdapat beberapa pertimbangan dalam memutuskan harga sebuah desain. Dalam artikel ini akan dikaji bagaimana menentukan harga sebuah desain dengan mempertimbangkan beberapa faktor dan aspek yang dapat memengaruhi sebuah desain.

\section{METODE}

Metode penelitian yang digunakan adalah studi empiris, observasi lapangan, serta metode kualitatif deskriptif dengan instrumen penelitiannya berupa wawancara mendalam dan focus group discussion terhadap beberapa narasumber yang merupakan desainer grafis freelance. Narasumber berasal dari beberapa kota di Jawa dan Sumatra seperti Jakarta, Surabaya, Bandung, Sidoarjo, Jogja, dan Batam. Narasumber yang dipilih merupakan mereka yang masih merintis karir di bidang desain grafis independen atau freelance di mana skala order atau project yang diterima belum terlalu besar seperti perusahaan nasional dan multinasional. Metode wawancara yang digunakan adalah semi terstuktur.

\section{PEMBAHASAN}

Dalam ilmu ekonomi proses penentuan harga sebuah produk, baik barang maupun jasa, seringkali dikaitkan dengan tujuannya. Menurut Fandy Tjiptono (Fandy Tjiptono, Ph.D., Strategi Pemasaran (edisi 4). Yogyakarta: Penerbit Andi. 2015), terdapat sejumlah tujuan penetapan harga berdasarkan orientasinya, di antaranya penetapan harga yang berorientasi laba, berorientasi volume, berorientasi permintaan pasar, berorientasi pangsa pasar, berorientasi aliran kas, berorientasi menyemai pesaing, berorientasi prestise, dan berorientasi status quo. Dari deretan orientasi tersebut lebih cocok jika diaplikasikan pada penetapan harga sebuah barang atau jasa yang dihasilkan untuk jual-beli, dihasilkan oleh perusahaan dan memiliki faktor-faktor yang terukur namun kurang cocok jika diaplikasikan pada bidang desain karena desain sendiri mengandung unsur seni di dalamnya. Penghargaan atas sebuah nilai ide tidak dapat diukur melalui sudut ekonomi namun lebih kepada pengukuran secara estetika dan kreativitas. Pengukuran pada proses penetapan harga sebuah desain lebih kepada proses dalam menghasilkan sebuah desain.

Menurut Surianto Rustan (Rustan, Surianto. 2015. Bisnis Desain Grafis. Jakarta: Batavia Imaji) umumnya klien, masyarakat, bahkan desainer yang berpikir bahwa satusatunya faktor penentu tarif/harga adalah dari spesifikasinya saja (bersifat fisik/tangible): ukuran, bahan, banyaknya/kuantitas, dll. Tidak memperhitungkan bobotnya (nonfisik/intangible): tingkat kesulitan, waktu yang dibutuhkan, kualitas karya prestasi desainernya, dll. Sehingga masih banyak faktor lain yang memengaruhi harga sebuah desain selain pada hasil yang tampak. Sehingga dalam proses menetapkan sebuah nilai atau value dalam sebuah desain, perlu memperhatikan beberapa faktor yang berkaitan 
dengan proses bagaimana sebuah desain tercipta. Faktor-faktor itu akan menjadi sebuah indikator penilaian dalam menentukan harga sebuah desain.

\section{Kriteria dan Faktor Indikator Penilaian}

Dalam bukunya yang berjudul bisnis desain, Surianto Rustan membagi beberapa faktor yang dapat memengaruhi tarif/harga sebuah desain di antaranya sebagai berikut:

1. Biaya dan Pengeluaran

Dalam menghasilkan sebuah desain tentu memerlukan proses, dalam berproses desainer tentu memiliki pengeluaran, baik secara pribadi seperti biaya hidup hingga fasilitas untuk menunjang riset dan penelitian dalam proses desain, hal tersebut perlu diperhitungkan sebelum menentukan harga.

\section{Supply and Demand}

Faktor kebutuhan dapat menaikkan tarif/harga desain mengingat usaha yang dilakukan juga menjadi berkali lipat seperti saat klien butuh desain cepat dengan deadline yang ketat, sebuah desain yang memerlukan keahlian khusus dan faktor-faktor yang memiliki tingkat prioritas lebih.

\section{Persepsi Konsumen}

Seperti penilaian produk pada umumnya, semakin positif persepsi konsumen terhadap suatu produk atau brand maka, nilai/value-nya akan semakin meningkat dan mendongkrak harga produk atau brand. Namun dalam desain, persepsi konsumen Indonesia terhadap desain saat ini adalah harga desain yang murah, mengingat desain merupakan jenis jasa yang dijual-belikan yang masih baru.

\section{Persaingan}

Faktor ini perlu diperhatikan desainer, dalam menjual sebuah produk atau jasa untuk menarik konsumen biasanya dilakukan pemangkasan harga agar dapat menang dalam persaingan. Hal tersebut juga berlaku dalam desain di mana ketika persaingan semakin ketat maka, akan terjadi perang harga dan mengakibatkan harga sebuah desain menjadi semakin murah.

Selain faktor-faktor tersebut terdapat juga faktor-faktor lain yang dapat memengaruhi indikator penilaian harga sebuah desain. Dari hasil wawancara dengan narasumber. Faktor-faktornya adalah sebagai berikut:

1. Jenis pekerjaan: desain logo, ilustrasi, desain 3D, videografi, fotografi, layout, dan lainnya memiliki tarif yang berbeda.

2. Bobot pekerjaan: kesulitan dan banyaknya tahapan dalam pengerjaan project.

3. Waktu pengerjaan: berhubungan dengan banyaknya pekerjaan yang harus dikerjakan.

4. SES Klien: klien yang besar dengan klien yang kecil akan mendapat harga yang berbeda.

Pembagian beberapa faktor tersebut berkaitan dengan skill dan pengalaman, tenaga yang dikeluarkan, serta waktu yang dihabiskan dalam pengerjaan. Klien kecil mendapat harga yang lebih rendah karena perbedaan tingkat ekonomi, serta lebih ke penanaman pentingnya desain dalam setiap lini kegiatan ekonomi. Masing-masing desainer memiliki indikator atau faktor-faktor yang berbeda, seperti daerah tempat tinggal 
desainer, upah minimum regional, bahkan kebudayaan juga turut berpengaruh dalam keputusan penetapan harga sebuah desain.

\section{Metode Penghitungan Harga}

Bagi desainer grafis atau desain komunikasi visual, ukuran penghitungan harga umumnya menggunakan ukuran tarif per jam atau hourly rate. Hal tersebut berkaitan dengan sistem kerja atau proses seorang desainer dalam menyelesaikan sebuah desain atau karya. Namun, terdapat juga desainer yang menjual desainnya secara lepas atau secara royalty. Menurut hasil wawancara dan FGD terdapat dua metode dalam menentukan tarif/harga desain.

\section{a. Metode Proses}

Dalam menghasilkan sebuah desain desainer tentu harus melalui beberapa proses desain diantaranya riset, main mapping, konsep, sketsa, rough desain hingga proses eksekusi dan tidak termasuk cetak atau proses produksi hanya proses konsep hingga menjadi final desain. Dengan mempertimbangkan hal tersebut maka dapat menggunakan rumusan sebagai berikut:

Bobot pekerjaan x Waktu Pengerjaan x Tarif per jam Pekerjaan = Harga Project

Selain itu seperti disebutkan sebelumnya yaitu faktor pekerjaan dapat memengaruhi perhitungan harga sebuah desain dengan contoh sebagai berikut:

\begin{tabular}{l|l|l|}
\hline Corporate Identity: & Layout: & Media Promosi: \\
Klien Kecil 1-5 juta & Klien Kecil 35.000-50.000/A4 & Klien Kecil 100.000-500.000 \\
Klien Besar 5-20 juta & Klien Besar 50-100.000/A4 & Klien Besar 1-5 juta \\
\hline
\end{tabular}

Desainer juga perlu merinci mengenai apa yang didapat oleh konsumen dari harga yang sudah dibayarkan, dengan contoh seperti berikut:

Corporate Identity (harga maksimal) $=$ riset desain, kriteria desain, sketsa, comprehensif (2x revisi), final logo, supergrafis, GSM, stationery, uniform.

Layout (harga maksimal) $=4$ template halaman, image editing, editorial, layout .

b. Metode Investasi

Menurut hasil dari Focus Group Discusses (FGD) beberapa desainer telah menerapkan metode investasi dalam menerapkan tarif/harga desain. Metode perhitungannya tidak jauh berbeda dengan metode proses sebelumnya namun ada faktor investasi yang juga diperhitungkan dalam proses perincian harga. 
Lutfi Tri Atmaji, Proses Penetuan Harga Desain...

Factor pertama adalah UMR atau Upah Minimum Regional dari konsumen. Desainer perlu memperhatikan UMR dari tempat asal konsumen sehingga harga yang

Harga indeks per jam = UMR : jumlah jam kerja : jumlah hari kerja dalam satu bulan

ditetapkan nantinya tidaklah sama atau pukul rata namun lebih mempertimbangkan dari mana konsumen atau project itu berasal. Dari satuan UMR dapat ditentukan berapa harga per/jam yang didapat oleh desainer dengan rumus sebagai berikut:

Contoh kasus sebagai berikut:

UMR Yogyakarta tahun 2017 ini adalah 1,572jt.

Rp 1,572,000 : $8: 22=\operatorname{Rp} 8.931 /$ jam, ini merupakan harga minimal kerja per jam, dengan jenis pekerjaan apapun.

Contoh kasus dengan jenis pekerjaan desain layout berupa poster event sebagai berikut;

1. Pencarian referensi $=2$ jam

2. Sketsa $=1$ jam

3. Tracing aset poster $=2 \mathrm{jam}$

4. Pengerjaan poster $=1 \mathrm{jam}$

5. Finishing $($ FA print $)=1$ jam

Total jam kerja $=7$ jam

Jumlah uang yang diterima $=7$ jam $x$ Rp $8.931=R p 62.517$

Jika sudah diketahui Harga Indeks per jam maka desainer bisa melanjutkan dengan menghitung nilai investasi. Perhitungan nilai investasi dapat mendongkrak nilai jual dari seorang desainer dalam menentukan harga sebuah desain. Harga indeks per jam dengan nilai investasi cara menghitungnya adalah sebagai berikut:

Total investasi (TI) dibagi waktu balik modal (WBM) dibagi satu tahun dibagi hari kerja (HK) dibagi jam kerja (JK)

TI : WBM : $12:$ HK : JK

Contoh kasus penghitungan harga indeks per jam dengan nilai investasi sebagai berikut:

1. Biaya SPP kuliah UPH 4 tahun $=120 \mathrm{jt}$

2. Laptop macbook pro ram 8 giga $=15 \mathrm{jt}$

3. Wacomm bamboo fun pro $=2 \mathrm{jt}$

4. Premium account $123 \mathrm{RF}$, freepik, shutterstock, imagestock, pixeden $=1 \mathrm{jt}$

5. Handphone iphone 6 dan mifi smartfren $=14 \mathrm{jt}$

6. Biaya operasional di kota Yogyakarta per bulannya $=2 \mathrm{jt}$

Total investasi yang dimiliki adalah $=154 \mathrm{jt}$, jika desainer berniat untuk balik modal dalam waktu 3 tahun maka:

Harga indeks per jam $=154$ jt $: 3$ tahun : 12 bulan : 22 hari kerja $: 8$ jam per hari $=\operatorname{Rp} 24,305$ 
Jika digabungkan dengan contoh kasus desain poster sebelumnya, maka jumlah uang yang diterima $=7$ jam $x \operatorname{Rp} 24,305=R p 170,138$.

Seorang desainer bekerja dengan proses kreatif dimana terdapat pemberian strategi komunikasi dan lain sebagainya. Rata-rata di setiap agensi kreatif, perbandingan kasta pekerjaan ini terhitung dengan 4:2:1. Perbandingan tersebut dapat dimasukkan dalam perhitungan Indeks Investasi sebelumnya yaitu Rp. 24, 305. Contoh aplikasinya sebagai berikut:

1. Pencarian referensi (strategi) $=2$ jam $x \operatorname{Rp} 97,220$

2. Sketsa (strategi) $=1$ jam $\times$ Rp 97, 220

3. Tracing aset poster (implementasi) $=2$ jam $x \operatorname{Rp~48,610~}$

4. Pengerjaan poster (implementasi) $=1$ jam $x$ Rp 48, 610

5. Finishing (FA print) (operasional) $=1$ jam $\times$ Rp 24, 305

Jumlah uang yang diterima adalah $\mathrm{Rp} 461,795$

Kedua metode yang telah dijabarkan sebelumnya dapat digunakan sebegai referensi dalam penetapan harga jual atau tarif bagi seorang freelance desainer. Desainer dapat menggunakan kedua metode dalam menentukan tarif atau harga sebuah desain atau menggunakan salah satu dari kedua metode.

\section{KESIMPULAN}

Bagi seorang freelance desainer faktor yang cukup penting dalam menaikkan tarif/harga sebuah desain adalah experience atau pengalaman, di mana semakin banyak pengalaman seorang desainer dalam mengerjakan sebuah proyek maka nilainya akan semakin naik karena dianggap sudah professional. Dari pengalaman yang tinggi juga seorang desainer akan memiliki diferensiasi dalam setiap karya desainnya hal tersebut menjadi diferensiasi dari kompetitornya. Dari experience juga seorang desainer akan dapat menaikkan nilai investasi sehingga harga atau tarif juga dapat terkatrol naik.

Agar mendapat banyak experience tentu seorang desainer harus sering mendapat banyak proyek maka sebaiknya freelance desainer pemula tidak tebang pilih dalam memilih sebuah proyek karena semua dimulai dari bagian terkecil hingga menjadi besar. Seorang desainer tidak seharusnya memukul rata semua harga dan sebaiknya memperhatikan siapa klien/konsumennya, dari mana klieannya berasal. Akan lebih baik jika desainer membuat sebuah paket yang disesuaikan dengan klien dan jenis pekerjaannya.

Semoga artikel ini dapat menjadi referensi bagi para desainer muda yang baru terjun di dunia desain grafis dan memutuskan menjadi seorang freelance desainer agar dapat menetapkan tarif/harga yang sesuai baik bagi desainernya maupun bagi konsumen/klien.

\section{KEPUSTAKAAN}

Fandy Tjiptono, Ph.D. 2015. Strategi Pemasaran (edisi 4). Yogyakarta: Penerbit Andi. Rustan, Surianto. 2015. Bisnis Desain Grafis. Jakarta: Batavia Imaji. 
Lutfi Tri Atmaji, Proses Penetuan Harga Desain...

Susanto, Mikke. 2011. Kelola Seni, Lukisan, Wayang, Film hingga Jazz. Yogyakarta: Penerbit Ombak

Macpal, Bellinda. Morasa, Jenny. Tirayoh, Victorina. 2014. “Analisis Perhitungan Harga Pokok Penjualan Barang Produksi pada Jepara Meubel di Kota Bitung”. Fakultas Ekonomi dan Bisnis, Jurusan Akutansi Universitas Sam Ratulangi Manado. Jurnal EMBA Vol. 2 No. 3 September 2014, hal. 1495-1503.

Wiryawan, Mendiola B. 2011. "Memikirkan Ulang Bisnis Model Berbasis Desain Komunikasi Visual". Humaniora Vol. 2 No. 1 April 2011: 643-651.

https://medium.com/@ connorgillivan/freelance-graphic-design-rates-2018-how-muchshould-you-pay-8002c649b44f 